\title{
Monitoramento de área de proteção ambiental com VANTs
}

\author{
Diego S. Pereira ${ }^{1}$, Maurício R. Silva ${ }^{1}$, Luís B. P. Nascimento ${ }^{1}$, \\ Bárbara G. S. Soares ${ }^{1}$, Daniel H. S. Fernandes ${ }^{1}$, Deyvid L. Leite ${ }^{1}$, Pablo J. Alsina ${ }^{1}$ \\ ${ }^{1}$ Departamento de Engenharia de Computação e Automação \\ Universidade Federal do Rio Grande do Norte (UFRN)$$
\text { Natal - RN - Brasil }
$$ \\ diego.pereiradifrn.edu.br, mauricio.silvalifpb.edu.br \\ \{lbruno, barbaragabriella, gordu, deyvidlucas\}@ufrn.edu.br, pablo@dca.ufrn.br
}

\begin{abstract}
This paper presents a proposal for a multi-UAV(Unmanned Aerial Vehicle) system to monitor the environmental protection area. For this it is made a specification of communication architecture for the network components, it choice a technology to data exchange and a brief presentation of computer vision system. As preliminary results, a comparison was made between the $S 1$ and S3 XBee modules to define which will be embedded in the aircraft.
\end{abstract}

Resumo. Este trabalho apresenta uma proposta para um sistema multi-VANT(Veículo Aéreo Não Tripulado) para monitoramento de área de proteção ambiental. Para tal é feita uma especificação de uma arquitetura de comunicação para os componentes de rede, escolha de uma tecnologia para troca de dados e uma breve apresentação do sistema de visão computacional. Como resultado preliminar foi realizada uma comparação entre os módulos XBee S1 e S3 para definir qual será embarcado nas aeronaves.

\section{Introdução}

Atualmente o estado do Rio Grande do Norte (RN) possui 4,5\% do seu território (238 mil hectares) distribuídos em oito unidades estaduais de conservação ambiental, das quais $2,58 \%$ estão no ecossistema marinho, $1,08 \%$ no ecossistema costeiro, $0,8 \%$ em ecossistema de mata atlântica e o restante na caatinga [IDEMA 2018]. Dentre as unidades instituídas pelo estado, a Área de Proteção Ambiental Jenipabu (APAJ) possui 1.881 hectares contemplando diversos ecossistemas e uma grande área de dunas, o Complexo Dunar de Jenipabu, região de intensa atividade turística durante todo o ano.

Ações antrópicas, tais como uso de automóveis em conjuntos de dunas e a formação de trilhas na vegetação são problemas que devem ser verificados a todo momento. Afinal, a vegetação local assegura que as dunas não sejam transportadas pela ação eólica, o que pode causar o desmatamento da restinga, e com isso, a dispersão das dunas, o que compromete estradas e residencias praianas, além do assoreamento das águas [Calvão et al. 2013].

Com base nos problemas supracitados, ações fiscalizatórias de monitoramento em tempo real se tornam necessárias. Diante desse contexto, é proposto um sistema multi-VANT de monitoramento capaz de identificar ações antrópicas consideradas ilegais 
em áreas de proteção ambiental, inicialmente, focadas na detecção de veículos em regiões não autorizadas. A partir disso, objetivo é permitir que as aeronaves, fazendo uso de um sistema embarcado, tenham a capacidade de identificar veículos em áreas de dunas. Detalhes do sistema proposto serão apresentados nas seções seguintes.

\section{Rede de comunicação para um sistema multi-VANT}

Um sistema multi-VANT necessita de uma rede de comunicação capaz de fornecer robustez, adaptabilidade, eficiência de recursos, escalabilidade, cooperatividade, heterogeneidade e autoconfigurabilidade. Nesse sentido, o controle físico das aeronaves, bem como seus recursos de navegação e comunicação, precisam ser integrados [Yanmaz et al. 2018]. Logo, é fundamental entender FANETs (Flying Ad hoc Networks), suas características e como viabilizar um sistema de comunicação capaz de atender tais exigências.

Uma FANET trata-se de uma rede ad hoc composta por aeronaves não tripuladas com capacidade de comunicação entre si e uma estação base. Os VANTs que compõe a rede podem superar a velocidade de $100 \mathrm{~m} / \mathrm{s}$ com movimentos em duas ou três dimensões, controlados de acordo com a missão. Com isso, é possível apresentar variações em sua topologia, as quais podem ser lentas ou rápidas, normalmente com movimentação ordenada ou sincronizada, dependendo do objetivo [Gupta et al. 2016].

Dentre as tecnologias a disposição para comunicação entre VANTs, a linha de módulos Digi XBee-PRO 900HP [XBee-PRO 2016], desenvolvida para troca de dados de longo alcance entre os dispositivos na frequência de $900 \mathrm{MHz}$, com uso do protocolo ZigBee (IEEE 802.15.4) adaptado à tecnologia DigiMesh apresenta-se com uma alternativa viável. Esse modelo possui capacidade de transmissão de dados de até $200 \mathrm{Kbps}$ com alcance de 14 km para transmissão entre dois nós.

\section{Sistema multi-VANT para monitoramento da APAJ}

O sistema multi-VANT proposto é constituído por aeronaves equipadas com câmeras, GPS, interfaces de comunicação, piloto automático, além de softwares embarcados em um microcomputador que viabilizam o funcionamento do sistema, por exemplo, o subsistema de processamento de imagens. Cada aeronave tem uma área específica de captura que, conforme a estratégia de varredura adotada, pode variar.

É possível até duas formas de comunicação, a primeira, V2V (VANT para VANT), troca de informações entre as aeronaves que compõe a rede de monitoramento, e V2E (VANT para Estação Base - EB), comunicação entre aeronave e a EB em terra, esta última responsável por ser a interface para o operador do sistema.

A rede do sistema multi-VANT proposta foi fisicamente construída com base em módulos XBee Pro conectados a microcomputadores do tipo Raspberry Pi com sistema operacional Raspbian Linux. Esses dispositivos serão embarcados em veículos aéreos quadrirrotor, equipados com GPS e placa controladora de piloto automático. A Figura 1 apresenta um VANT quadrirrotor Phantom 3 Standart, Figura 1(a), o microcomputador Raspberry Pi com módulo XBee, Figura 1(b), e a estação base, Figura 1(c).

O sistema de comunicação da estação base em terra e o VANT faz uso de transceptores XBee/PRO-S3 com potência de $250 \mathrm{~mW}$ na frequência de $920 \mathrm{MHz}$. O 


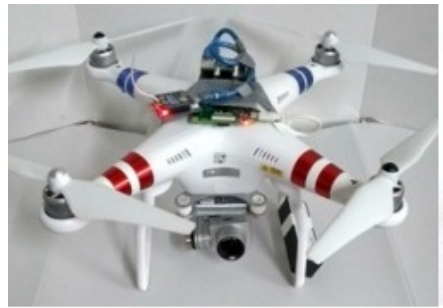

(a)

VANT com sistema de comunicaçäo embarcado

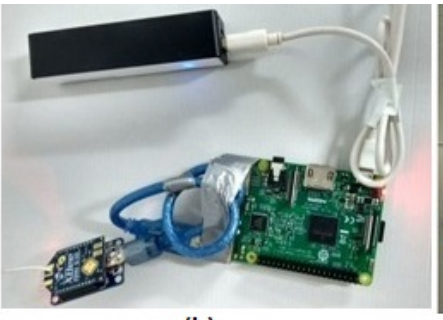

(b)

Sistema de comunicação com módulo XBee

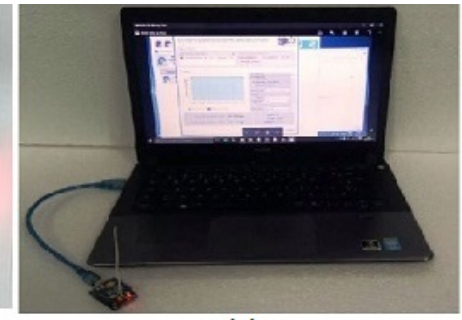

(c)

Estaçäo base equipada com módulo XBee

Figura 1. Dispositivos utilizados para os testes da arquitetura de hardware.

sistema conta com antenas omnidirecional filamentares de ganho 1,5 $\mathrm{dBi}$. O uso de antenas omnidirecionais proporciona uma maior capacidade de recepção das aeronaves e a estação terrena, uma vez que, permite receber a mesma potência do sinal independente da direção que o VANT se desloca. O sistema conta com um receptor com sensibilidade de $-100 \mathrm{dBm}$ permitindo um maior raio de atuação das aeronaves.

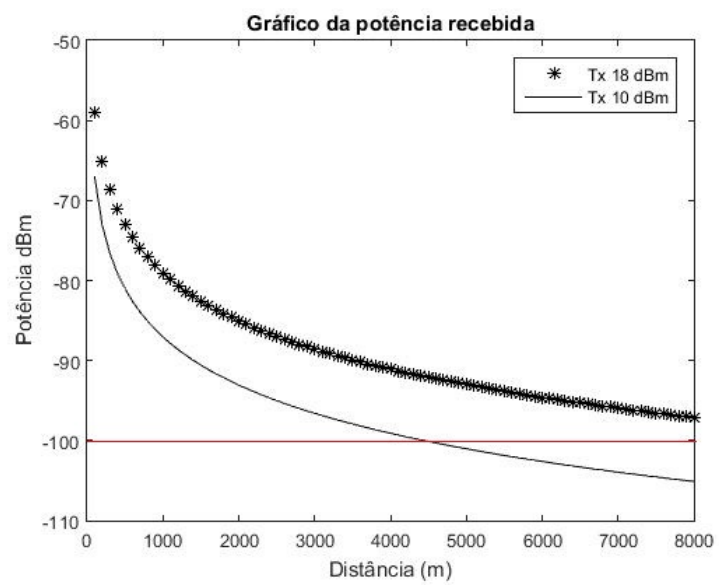

Figura 2. Perda de percurso dos sinais de transmissão para comunicação.

A Figura 2 mostra a perda de percurso para um link de rádio frequência com visada direta para as versões $\mathrm{S} 3(18 \mathrm{dBm})$ e $\mathrm{S} 1(10 \mathrm{dBm})$ dos transceptores. É possível perceber que o dispositivo XBee S3 consegue uma potência de chegada ao receptor maior que o limiar mínimo (linha vermelha) especificado pelo manual para uma distância de até $8 \mathrm{~km}$. Tal consideração se faz necessária pois uma condição de trabalho para garantir operacionalidade do sistema é que um dos VANTs mantenha visada direta com a estação base a uma distância segura.

\subsection{Subsistema de visão computacional}

Através da câmera embarcada no VANT é possível extrair informações das imagens em tempo real para detectar irregularidades no ambiente. Para o estudo de caso proposto, existem subáreas bem demarcadas da APAJ nas quais não é permitido a presença de pessoas, carros, construções ou qualquer ação de origem antrópica. Nesse sentido, faz-se necessário um algoritmo em execução no sistema embarcado capaz de interpretar o conteúdo da imagem capturada pelo VANT, quando uma irregularidade é detectada, 
a imagem e as coordenadas geográficas (obtidas via GPS) são enviadas para a estação base, local onde encontra-se o operador do sistema e responsável por notificar a equipe de fiscalização em terra para averiguação da ocorrência. Dessa forma, será utilizada a biblioteca OpenCV (Open Source Computer Vision Library) para aquisição e tratamento das imagens obtidas pela aeronave que serão entradas para o treinamento de redes neurais [Narayanan et al. 2018, Tayara et al. 2018]. A Figura 3 simula o resultado da detecção de um veiculo em área de dunas.

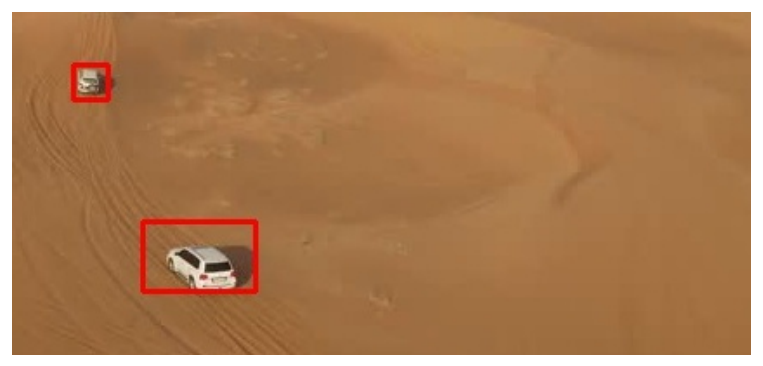

Figura 3. Detecção de Veiculo

\section{Considerações finais}

Este trabalho apresentou uma proposta de um sistema multi-VANT equipado com um sistema embarcado para o monitoramento de áreas de proteção ambiental com o propósito de auxiliar na fiscalização e proteção dessas áreas. Como caso de estudo inicial, foi citado Área de Proteção Ambiental de Jenipabu com intuito de executar detecção de carros em área de dunas. Também foi feita uma breve análise da perda de percurso dos sinais de transmissão para comunicação utilizando os módulos XBee S1 e S3, na qual o S3 apresentou melhores resultados.

\section{Referências}

Calvão, T., Pessoa, M. F., and Lidon, F. C. (2013). Impact of human activities on coastal vegetation-a review. Emirates Journal of Food and Agriculture, 25(12):926.

Gupta, L., Jain, R., and Vaszkun, G. (2016). Survey of important issues in uav communication networks. IEEE Communications Surveys \& Tutorials, 18(2):1123-1152.

IDEMA (2018). Disponível em: http://www.idema.rn.gov.br. Acesso em: 26 Mar. 2018.

Narayanan, P., Borel-Donohue, C., Lee, H., Kwon, H., and Rao, R. (2018). A real-time object detection framework for aerial imagery using deep neural networks and synthetic training images. In Signal Processing, Sensor/Information Fusion, and Target Recognition XXVII, volume 10646, page 1064614. SPIE.

Tayara, H., Soo, K. G., and Chong, K. T. (2018). Vehicle detection and counting in high-resolution aerial images using convolutional regression neural network. IEEE Access, 6:2220-2230.

XBee-PRO, U. G. (2016). User Guide - XBee-PRO 900HP/XSC RF Modules S3 and S3B. Digi International, Minnetonka, MN.

Yanmaz, E., Yahyanejad, S., Rinner, B., Hellwagner, H., and Bettstetter, C. (2018). Drone networks: Communications, coordination, and sensing. Ad Hoc Networks, 68:1-15. 